\title{
Spectroscopic diagnostics of a high-frequency dielectric barrier discharge of atmospheric pressure in mixtures of cadmium diiodide vapor with neon and small additions of xenon
}

\section{A. Malinina}

Uzhhorod National University, Faculty of Physics, Department of Quantum Electronics, Narodna pl. 3., Uzhhorod, Ukraine

(Received: 12. Sep. 2020, Accepted: 13. Nov. 2020, Published online: 16. Nov. 2020)

Diagnostics of the emission spectra of a gas-discharge plasma of a dielectric barrier discharge of atmospheric pressure in mixtures of cadmium diiodide vapor with neon and small additions of xenon is carried out. A gas-discharge plasma was created and the components were excited by a high-frequency dielectric barrier discharge at a sinusoidal voltage pulse repetition rate of up to $140 \mathrm{kHz}$. Emission of exciplex molecules of cadmium monoiodide with a maximum emission at a wavelength of $\lambda=655 \mathrm{~nm}$ and xenon iodide with a maximum of radiation at wavelengths $\lambda=253$ and $\lambda=320 \mathrm{~nm}$, excimer molecules of iodine, lines of atoms of cadmium, iodine, neon and xenon was revealed. It was found that at at gas temperatures of the mixtures under study above $150{ }^{\circ} \mathrm{C}$, the predominance of radiation from exciplex molecules of cadmium monoiodide is observed. The reason for the increased brightness of the emission of exciplex molecules of cadmium monoiodide in mixtures of cadmium diiodide vapor with neon and xenon additive is established. The regularities in the spectral characteristics of radiation in the mixtures under study are discussed. A high-frequency dielectric barrier discharge of atmospheric pressure in mixtures of cadmium diiodide vapor with neon and xenon is of interest for creating a multi-wavelength excilamp in the UV and visible spectral ranges.

(C) G-Labs 2020

(DOI: 10.31281/jtsp.v1i1.14)

antonina.malinina@uzhnu.edu.ua

\section{Introduction}

Diagnostics of plasma radiation spectra is an important tool for studying physicochemical processes occurring in plasma in spontaneous and coherent radiation sources. Data of this kind make it possible to reveal the features of the plasma radiation spectra of different component composition and to optimize the spectral and energy characteristics of radiation sources [1]. Plasma based on mixtures of cadmium diiodide vapor with inert gases is being investigated in order to create a highly efficient coherent and spontaneous source of selective radiation of exciplex cadmium monoiodide molecules in the red spectral range [2-4]. In a gas-discharge plasma on a mixture of cadmium diode vapor with xenon and neon at amospheric pressure, the conditions were revealed under which the excitation and emission of simultaneously exciplex molecules of cadmium monoiodide (Cdl *) and xenon iodine (Xel *) with a wavelength at the maximum radiation intensity $\lambda_{\max }=650 \mathrm{~nm}$ and $\lambda_{\text {max. }}=253 \mathrm{~nm}$, is occurred [5]. The working gas mixtures were excited by a highfrequency power supply with a harmonic output voltage, which is important for creating powerful spectral sources of simultaneous radiation in the red and ultraviolet spectral ranges.

The purpose of the research was to diagnose the emission spectra of gas-discharge plasma in mixtures of cadmium diiodide vapor with neon 
and xenon with the excitation of working gas mixtures by a high-frequency power source with a harmonic output voltage, with the possibility of frequency tuning up to $140 \mathrm{kHz}$, to determine the plasma parameters and, on the basis of them, to establish the reduced electric field at which the maximum contribution of the discharge power to the excitation of exciplex molecules of cadmium monoiodide and xenon iodide will be observed.

\section{Experimental technique and methods}

Fig. 1 shows the main units of an experimental setup for studying the optical characteristics of a gas-discharge plasma in mixtures of cadmium diiodide vapor, neon and xenon. Gas-discharge plasma was excited by a dielectric barrier discharge $(B D)$ in a small cylindrical emitter with one dielectric barrier with a capacity of $C_{d}=25 \mathrm{pF}$, made of a quartz tube. The outer diameter of the tube (5) with a wall thickness of $1 \mathrm{~mm}$ was 8.8 $\mathrm{mm}$. Inside, along the axis, there was a molybdenum electrode (4) $1 \mathrm{~mm}$ in diameter. The discharge gap was $2.9 \mathrm{~mm}$. The outer electrode (6), which was located on the surface of the tube, was made of a grid (radiation transmittance $T=$ $50 \%$ ) and had a length of $30 \mathrm{~mm}$.

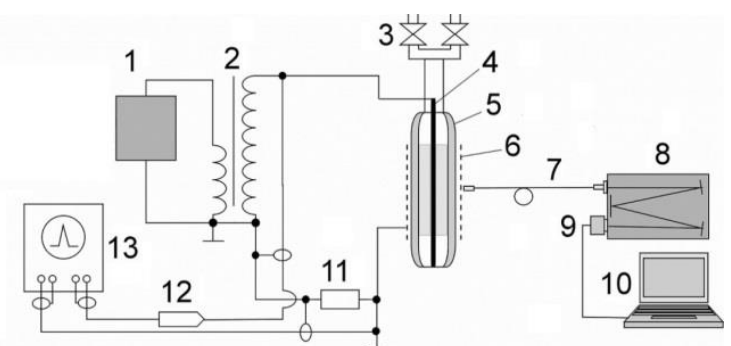

Figure 1: Diagram of the experimental setup: 1 - a pulse generator, 2 - a high-voltage transformer, 3 - a system for pumping and inlet gases, 4 - an electrode, 5 - a quartz tube, 6 - a grid (external electrode), 7 - an optical fiber, 8 - a monochromator, 9 - CCD detector, 10 - personal computer, 11 - shunt, 12 - voltage divider, 13 digital oscilloscope.

Excitation of working gas mixtures in a dielectric barrier discharge of atmospheric pressure was carried out by a power supply with a harmonic shape of the output voltage, with the possibility of tuning the frequency in the range of $1-140 \mathrm{kHz}$, with an amplitude of up to $7 \mathrm{kV}$. The master generator formed pulses of alternating polarity, which were fed to the output step-up transformer. The time dependences of the voltage at the source electrodes and the discharge current were recorded with an HP 54820A Infinium two-beam digital oscilloscope. The signals to the oscilloscope were fed from a Tektronix P6015A voltage divider 12 and a shunt 11 , respectively.

The discharge radiation was recorded in the direction perpendicular to the side surface of the quartz tube and analyzed in the spectral range 200 - $900 \mathrm{~nm}$. The emission spectra were recorded using a Jobin Yvon TRIAX 550 monochromator (1200 lines/mm grating, quartz optical fiber, Spectrum ONE CCD detector cooled by liquid nitrogen). The spectral resolution of the registration system was $0.05 \mathrm{~nm}$. The registration system was calibrated in the $200-400 \mathrm{~nm}$ region using a deuterium lamp, and in the $400-900 \mathrm{~nm}$ region using a reference tungsten lamp.

The working gas mixtures were prepared directly in the radiation source. The salt of cadmium diiodide $\left(\mathrm{Cdl}_{2}\right)$ in the amount of $100 \mathrm{mg}$ was evenly loaded into the emitter. After loading the salt, the source was dehydrated by heating at a temperature of $\sim 100^{\circ} \mathrm{C}$ and pumping out for 2 $\mathrm{h}$. The value of the partial pressure of $\mathrm{Cdl}_{2}$ vapor was determined from the temperature of the coldest point of the emitter based on the interpolation of the reference data from [6] and in our conditions was $0.01-30 \mathrm{~Pa}$. The partial pressure of gases was measured with an accuracy of $10 \mathrm{~Pa}$.

\section{Results and discussion}

In the course of the experiments, a mixture of cadmium diiodide vapor with neon, as well as mixtures of cadmium diiodide vapor, neon, and xenon were investigated at different partial pressures. Immediately after the initiation of a dielectric barrier discharge of atmospheric pressure in mixtures of cadmium diiodide with inert gases, a filamentary regime of dielectric barrier discharge burning was observed. With an increase in the pump pulse repetition rate, a change in the shape of microdischarges was observed from cylindrical (at $\mathrm{f} \sim 10 \mathrm{kHz}$ ) to coneshaped - with a top on a metal electrode and a base on the inner surface of a quartz tube (at $f$ $100 \mathrm{kHz}$ ). As the mixture warmed up, the discharge color became pink. In this case, a more diffuse and homogeneous nature of the discharge was observed, and the brightness contrast in the volume discharge and filaments was significantly smoothed out. 
In the electrical characteristics of a dielectric barrier discharge on mixtures of $\mathrm{Cdl}_{2}$ vapor with neon and xenon, similar regularities were observed, as in mixtures of $\mathrm{ZnI}_{2}$ vapors with gases [7]. At low pulse repetition rates $(f \sim 10 \mathrm{kHz})$ in each half-period of the applied voltage $U, a$ series of sharp picks of different amplitudes and approximately the same duration were observed on the oscillogram of the recorded current on the bias current curve. Each current pick is caused by a set of micro-discharges - filaments, which appear in the discharge gap and are statistically distributed over time. The amplitude of the peaks did not exceed $20 \mathrm{~mA}$ with a duration of up to 200 ns. With an increase in the temperature of the mixture at a fixed voltage and pulse repetition rate, the number of current picks increased. At the same time, an increase in the pulse repetition rate at a fixed voltage led to a decrease in the number of current picks in the train. The first pick of current with increasing $U$ moved more and more to the left from the maximum of the applied voltage, and at large amplitudes of $U$, the first pick occurred already in the phase of the negative applied voltage. As in [8], current peaks of positive polarity always occurred on the voltage phase with a positive derivative $\mathrm{dU} / \mathrm{dt}>0$.

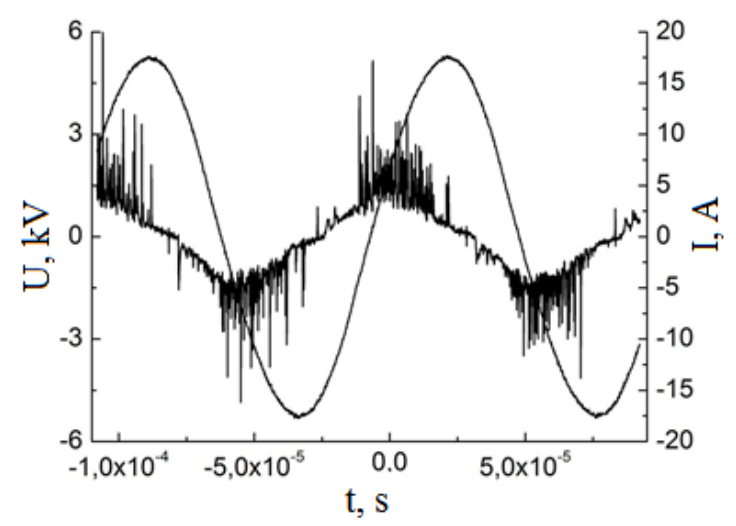

Figure 2: Oscillograms of the voltage and current pulses of the dielectric barrier discharge in the mixture $\mathrm{Cdl}_{2} / \mathrm{Ne}=20 \mathrm{~Pa} / 101.3 \mathrm{kPa}, \mathrm{f}=10 \mathrm{kHz}$.

Typical survey spectra of BR plasma radiation in a double mixture of cadmium diiodide vapor with neon and a ternary mixture of cadmium diiodide, neon, and xenon are shown in Fig. 3-5. In the spectra in the visible range, a spectral band with a maximum at $\lambda=655 \mathrm{~nm}$ stands out, which has a weakly resolved vibrational structure and corresponds to the electronic-vibrational transition $B^{2} \Sigma^{+}{ }_{1 / 2} \rightarrow X^{2} \Sigma^{+}{ }_{1 / 2}$ exciplex molecules of cadmium monoiodide [9]. Radiation of $\mathrm{Cdl}(B \rightarrow X)$ appears starting from $\lambda \sim 400 \mathrm{~nm}$, its main part is concentrated in the range of $635-660 \mathrm{~nm}$. The shape of the spectral band of the electronicvibrational transition $B^{2} \Sigma^{+}{ }_{1 / 2} \rightarrow X^{2} \Sigma^{+}{ }_{1 / 2}$ of the exciplex cadmium monoiodide molecules is similar to the spectral bands corresponding to the $B \rightarrow X$ transition in mercury halides and zinc, namely: a steeper increase in intensity from the side of the long-wavelength region and a slow decrease in the short-wavelength region $[7,10]$. At atmospheric pressure of the mixture, due to the completeness of the vibrational relaxation, transitions occur mainly from the lower vibrational levels of the excited electronic state $v^{\prime}=0-2 \rightarrow v^{\prime \prime}=61,62$. The spectral bandwidth at half maximum for $C d l(B \rightarrow X)$ was $11-12 \mathrm{~nm}$. With an increase in the pump pulse repetition rate, the brightness of the $\mathrm{Cdl}(\mathrm{B} \rightarrow \mathrm{X})$ spectral band increased, while its shape and the position of the emission maximum did not change (the spectral band brightness was understood as the area under the curve in the spectrum).

All spectra also contained atomic cadmium lines, the most intense of which are the $5 p \rightarrow 5 s$ resonance lines (228.8 and $326.1 \mathrm{~nm}$ ) in the UV region, and in the visible - the $6 s \rightarrow 5 p$ triplet $(467.8,480.0$, and $508.6 \mathrm{~nm})$ and the $5 d \rightarrow 5 p$ line $(643.8 \mathrm{~nm})$. In addition, the resonance line of iodine $6 s \rightarrow 5 p(206.2 \mathrm{~nm})$ [11] and spectral bands of molecular iodine were observed, the most intense of which was the band $I_{2}\left(D^{\prime} \rightarrow A^{\prime}\right)$ with a maximum at $\lambda=342 \mathrm{~nm}$ [9]. The intensity of the atomic lines and the brightness of the molecular bands strongly depended on the temperature of the working mixture. The intensity of the cadmium lines increased with increasing temperature, while the intensity of the atomic lines of iodine and the brightness of the spectral bands of molecular iodine decreased. In the spectral range 315 - $425 \mathrm{~nm}$, bands of molecular nitrogen corresponding to the transition of the second positive nitrogen system were also observed [9]. They manifested themselves as a result of a discharge (parasitic) burning in air between the outer surface of the quartz tube and the grid. At a temperature of $<1000{ }^{\circ} \mathrm{C}$, spectral bands were observed in all studied mixtures in the spectral range $420-480$ $\mathrm{nm}$, which were identified with the emission of $\mathrm{I}_{2}$ $(B \rightarrow X)$ molecules [9].

In the emission spectra of a dielectric barrier discharge in a mixture of cadmium diiodide vapor with neon (Fig. 3) in the spectral range of 580 $720 \mathrm{~nm}$, atomic lines of a buffer gas neon were observed, the intensity of which significantly decreased as the working medium was heated and was caused by a decrease in the electron temperature in the discharge with an increase in 
concentration of easily ionized particles, in particular, cadmium diiodide molecules and cadmium atoms, which led to a change in the efficiency of excitation of neon lines.

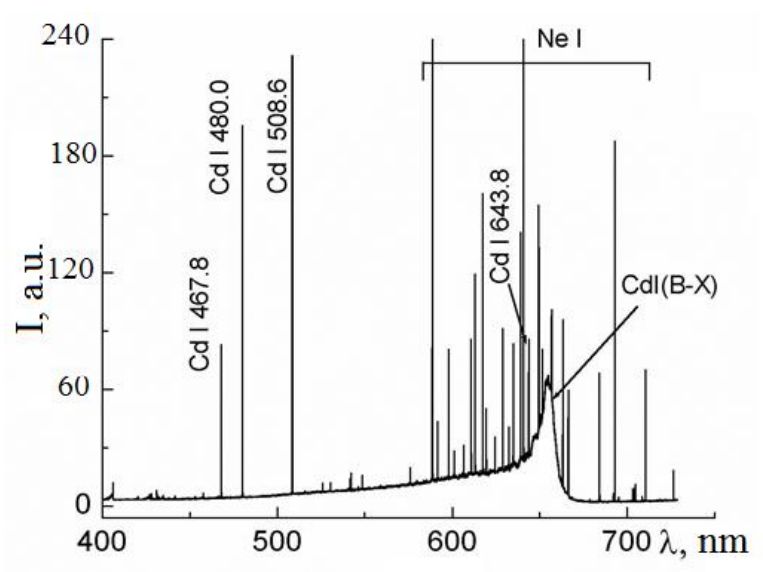

Figure 3: Survey spectrum of radiation of a dielectric barrier discharge in the visible region on a mixture $\mathrm{Cdl}_{2} / \mathrm{Ne}=20 \mathrm{~Pa} / 101.3 \mathrm{kPa}$.

The survey spectrum of radiation of a dielectric barrier discharge in the visible region on a mixture $\mathrm{Cdl}_{2} / \mathrm{Ne}=20 \mathrm{~Pa} / 101.3 \mathrm{kPa}$. In the emission spectra of the ternary mixture $\mathrm{Cdl}_{2} / \mathrm{Xe}$ / Ne (Figs. 4, 5), in addition to the emission of $\mathrm{Cdl}$ $(B \rightarrow X)$, at a mixture temperature up to $\sim 250{ }^{\circ} \mathrm{C}$, intense spectral bands of emission from exciplex molecules Xel $(B \rightarrow X)$ and $\mathrm{Xel}(B \rightarrow A)$ with maxima at 253 and $320 \mathrm{~nm}$, were observed (Fig. 5) [12].

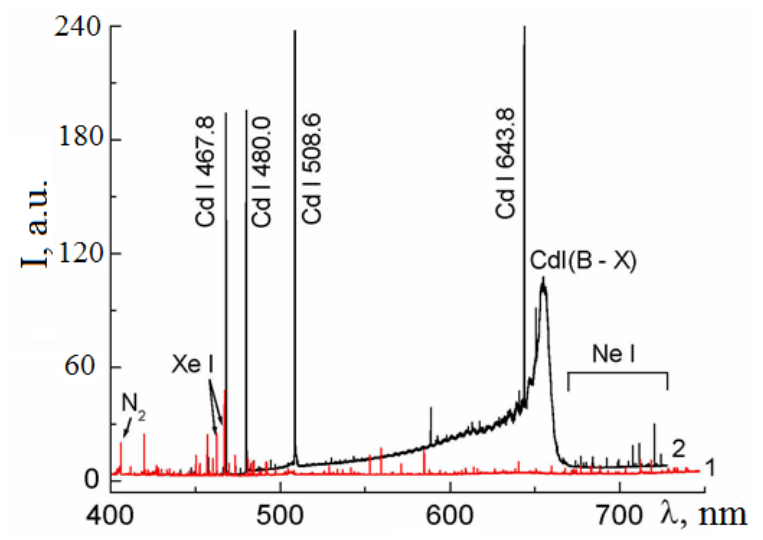

Figure 4: The survey spectrum of radiation of a dielectric barrier discharge in the visible region in mixtures: $1-\mathrm{Cdl}_{2} / \mathrm{Xe} / \mathrm{Ne}=0.01 \mathrm{~Pa} / 8 \mathrm{kPa} /$ $101.3 \mathrm{kPa}, 2-\mathrm{Cdl}_{2} / \mathrm{Xe} / \mathrm{Ne}=30 \mathrm{~Pa} / 8 \mathrm{kPa} / 101.3$ $\mathrm{kPa}$.

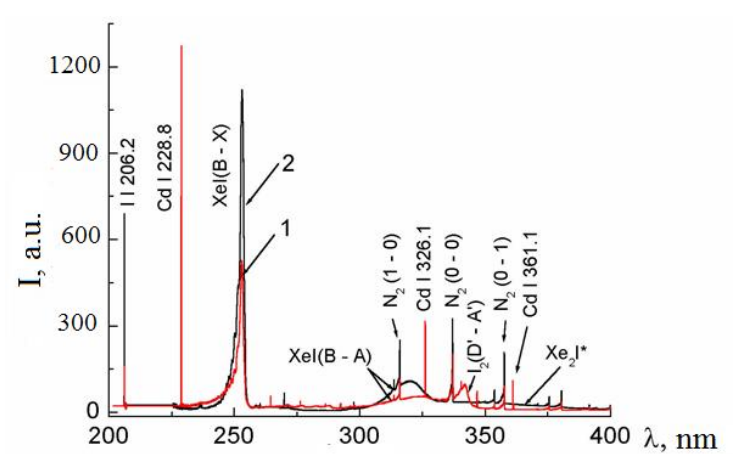

Figure 5: The survey spectrum of radiation of a dielectric barrier discharge in the UV region in mixtures: $1-\mathrm{Cdl}_{2} / \mathrm{Xe} / \mathrm{Ne}=0.15 \mathrm{~Pa} / 4 \mathrm{kPa} /$ $101.3 \mathrm{kPa}, 2-\mathrm{Cdl}_{2} / \mathrm{Xe} / \mathrm{Ne}=0.05 \mathrm{~Pa} / 8 \mathrm{kPa} /$ $101.3 \mathrm{kPa}$.

It should be noted that, with the addition of xenon, the number of neon lines in the spectrum sharply decreased. With an increase in the partial pressure of xenon, the brightness of $\mathrm{Xel}(\mathrm{B} \rightarrow \mathrm{X})$ radiation increased, and in the $330-400 \mathrm{~nm}$ region, a broad continuum was observed associated with the formation of $\mathrm{Xe}_{2} \mid$ * molecules [12]. In this mixture, the xenon emission spectrum is represented by atomic lines, among which the most intense in the visible region are $7 \mathrm{p} \rightarrow 6 \mathrm{~s}$ at 462.4 and $467.1 \mathrm{~nm}$, and in the near infrared $-6 p \rightarrow 6 s$ at 823.2, 828.0, 834.7, 840.9 and $881.9 \mathrm{~nm}$ [11]. With an increase in the mixture's temperature, the intensity of the xenon lines in the IR region decreased by a factor of 4-5.

The brightness indices of the spectral emission band of $\mathrm{Cdl}(\mathrm{B} \rightarrow \mathrm{X})$ in the $\mathrm{BR}$ in mixtures of cadmium diiodide vapor, neon, and xenon of different partial ratios of the mixture components are given in Table 1. Optimal in terms of the maximum yield of $\mathrm{Cdl}(\mathrm{B} \rightarrow \mathrm{X})$ is the $\mathrm{Cdl}_{2} / \mathrm{Xe} / \mathrm{Ne}$ $=22 \mathrm{~Pa} / 4 \mathrm{kPa} / 101.3 \mathrm{kPa}$ mixture. The brightness of $\mathrm{Cdl}(\mathrm{B} \rightarrow \mathrm{X})$ radiation in a mixture of cadmium diiodide vapor, neon, and xenon is $11 \%$ higher than in a mixture of cadmium diiodide vapor and neon. With an increase in the partial pressure of xenon, the following regularities appeared. First, under unchanged external conditions, the temperature of the mixture increased (from $345^{\circ} \mathrm{C}$ to $360^{\circ} \mathrm{C}$ ) and, as a consequence, the partial pressure of cadmium diiodide vapor. Second, a monotonic increase in the brightness of $\mathrm{Cdl}^{*}$ radiation was observed, and a maximum was reached in the region of xenon partial pressure equal to 2 - $4 \mathrm{kPa}$. 


\begin{tabular}{|c|c|c|}
\hline Mixture & $\begin{array}{l}\text { Partial pressures of the } \\
\text { components }\end{array}$ & $\begin{array}{c}\text { Brightness } \operatorname{Cdl}(B \rightarrow X) \text {, } \\
\text { a.u. }\end{array}$ \\
\hline $\mathrm{Cdl}_{2} / \mathrm{Ne}$ & $20 \mathrm{~Pa} / 101.3 \mathrm{kPa}$ & 0.79 \\
\hline $\mathrm{CdI}_{2} / \mathrm{Xe} / \mathrm{Ne}$ & $\begin{array}{l}20 \mathrm{~Pa} / 0.6 \mathrm{kPa} / 101.3 \mathrm{kPa} \text {. } \\
20 \mathrm{~Pa} 0.9 \mathrm{kPa} / 101.3 \mathrm{kPa} \text {. } \\
21 \mathrm{~Pa} / 1.23 \mathrm{kPa} / 101.3 \mathrm{kPa} \text {. } \\
22 \mathrm{~Pa} / 2.5 \mathrm{kPa} / 101.3 \mathrm{kPa} \text {. } \\
22 \mathrm{~Pa} / 4 \mathrm{kPa} / 101.3 \mathrm{kPa} \text {. } \\
23 \mathrm{~Pa} / 4.5 \mathrm{kPa} / 101.3 \mathrm{kPa} \text {. } \\
24 \mathrm{~Pa} / 5.5 \mathrm{kPa} / 101.3 \mathrm{kPa} \text {. } \\
26 \mathrm{~Pa} / 8 \mathrm{kPa} / 101.3 \mathrm{kPa} \text {. }\end{array}$ & $\begin{array}{l}0.29 \\
0.54 \\
0.72 \\
0.96 \\
1 \\
0.89 \\
0.84 \\
0.89\end{array}$ \\
\hline
\end{tabular}

Table 1: Brightness of the spectral band of $\mathrm{Cdl}(\mathrm{B} \rightarrow \mathrm{X})$ emission in a dielectric barrier discharge in mixtures of cadmium diiodide vapor with neon and xenon.

The presence in the spectra of the studied mixtures (Fig. 1-3) of atomic lines of cadmium and inert gases, as well as the molecular bands of $\mathrm{Cdl}^{*}$, $\mathrm{I}_{2}{ }^{*}, \mathrm{Xel}^{*}$ and $\mathrm{Xe}_{2} \mathrm{l}^{*}$, is caused by plasma-chemical reactions of the interaction of electrons of different energies with cadmium diiodide molecules, rare gas atoms and by reactions of recombination of positive and negative ions. Thus, the appearance of emission of the observed spectral bands and lines probably occurs in the following reactions $[2,3,12-16]$ :

$$
I+e
$$

$C d I_{2}+e \rightarrow \mathrm{CdI}_{2}\left({ }^{3,1} \Sigma^{+} u\right) \rightarrow C d I\left(B^{2} \Sigma^{+} 1 / 2\right)+I^{-}$

$\mathrm{CdI}_{2}+\mathrm{Xe}^{*} \rightarrow \mathrm{CdI}_{2}\left({ }^{3,1} \Sigma^{+} \mathrm{u}\right) \rightarrow \mathrm{CdI}\left(B^{2 \Sigma^{+}} 1 / 2\right)+\mathrm{I}+\mathrm{Xe}$,

$C d I\left(B^{2} \Sigma^{+} 1 / 2\right) \rightarrow C d I\left(X^{2} \Sigma^{+} 1 / 2\right)+h v$,

$\lambda_{\max }=655 \mathrm{~nm}$

$$
\begin{gathered}
C d I_{2}+e \rightarrow C d^{*}+I+I \\
C d I_{2}+e \rightarrow C d^{*}+I^{*}+I+e,
\end{gathered}
$$

$$
\begin{gathered}
\mathrm{CdI}_{2}+e \rightarrow \mathrm{Cd}^{*}+\mathrm{I}_{2}{ }^{*}+e, \\
\mathrm{CdI} I_{2}+e \rightarrow C d^{*}+I_{2}, \\
C d I_{2}+e \rightarrow C d^{*}+\mathrm{I}_{2}+2 e, \\
C d I_{2}+e \rightarrow C d^{*}+I^{+}+I+2 e, \\
C d^{*} \rightarrow C d+h v,
\end{gathered}
$$

$\lambda=228.8 \mathrm{~nm}, 326.1 \mathrm{~nm}, 467.8,480.0 \mathrm{~nm}, 508.6 \mathrm{~nm}$ and $643.8 \mathrm{~nm}$.

$$
I^{*} \rightarrow I+h v,
$$

$\lambda=206.2 \mathrm{~nm}$.

$$
I_{2}^{*} \rightarrow I_{2}+h v
$$

$\lambda=342 \mathrm{~nm}, 420-480 \mathrm{~nm}$.

$$
N e+e \rightarrow N e^{*}+e
$$

$$
N e^{*} \rightarrow \mathrm{Ne}+h v
$$

$$
\lambda=580-720 \mathrm{~nm} .
$$




$$
\begin{gathered}
X e+e \rightarrow X e^{*}+e \\
X e^{*} \rightarrow X e+h v
\end{gathered}
$$

$\lambda=462.4 \mathrm{~nm}, 467.1 \mathrm{~nm}, 823.2 \mathrm{~nm}, 828.0,834.7 \mathrm{~nm}$, $840.9 \mathrm{~nm}, 881.9 \mathrm{~nm}$.

$$
\begin{aligned}
& X e^{*}+X e+M \rightarrow X e 2^{*} \\
& X e^{*}\left(\mathrm{Xe}_{2}^{*}\right)+\mathrm{I}_{2} \rightarrow \mathrm{XeI}^{*}+(\mathrm{Xe})+I_{1} \\
& \mathrm{Xe}+e \rightarrow \mathrm{Xe}++2 e \\
& X e^{+}+I_{2}+M \rightarrow X e I^{*}+I+M, \\
& \mathrm{Xe}^{+}+\mathrm{I}+\mathrm{M} \rightarrow \mathrm{XeI}^{*}+M,
\end{aligned}
$$

where $\mathrm{M}$ - third particle

$$
X e I^{*} \rightarrow X e I+h v
$$

$\lambda=253_{\text {нм, }} 320_{\text {нм. }}$

$$
\begin{gathered}
\mathrm{XeI}^{*}+2 \mathrm{Xe} \rightarrow \mathrm{Xe}_{2} I^{*}+\mathrm{Xe}, \\
\mathrm{Xe}_{2} I^{*} \rightarrow \mathrm{Xe}_{2} I+h v
\end{gathered}
$$

$\lambda=330-400 \mathrm{~nm}$.

Features in the emission spectra of BR plasma on a ternary mixture with Xe (Fig. 3), namely, a sharp decrease in the number of neon lines in the spectrum upon addition of xenon, are caused by the Penning ionization of $\mathrm{Xe}$ [17]:

$$
\mathrm{Ne}^{*}+\mathrm{Xe} \rightarrow \mathrm{Ne}+\mathrm{Xe}^{+}+e
$$

The ratios of the intensities of the spectral bands and lines in the spectra (Figs. 1-3) depend on the rate constants of excitation, which in turn are determined by the effective cross sections and distribution functions of electrons on the energies in the gas-discharge plasma of a dielectric barrier discharge $[1,18]$.

To clarify the reasons for the increase in the brightness of the emission of $\mathrm{Cdl}^{*}$ molecules in a mixture with an addition of xenon, we studied the plasma parameters.

\section{Plasma parameters}

The plasma parameters were determined numerically and calculated as total integrals of the electron energy distribution function (EEDF) based on the Boltzmann equation in the two-term approximation [19]. The EEDF calculations were carried out using the well-known Bolsig+ program
[20]. Based on the EEDF obtained, a number of plasma parameters were determined depending on the value of the reduced electric field (the ratio of the electric field strength $(E)$ to the total concentration of neon, xenon, and a small admixture of cadmium diiodide vapor $(\mathrm{N})$ ). The range of variation of the parameter $\mathrm{E} / \mathrm{N}=1-200 \mathrm{Td}$ $\left(1 \cdot 10^{-17}-2 \cdot 10^{-14} \mathrm{~V} \cdot \mathrm{cm}^{2}\right)$ included the values of the parameter $\mathrm{E} / \mathrm{N}$, which were realized in the experiment.

All calculations were performed for $\mathrm{a} \mathrm{CdI}_{2}: \mathrm{Ne}=20$ Pa: $101.3 \mathrm{kPa}$ mixture at a total mixture pressure of $101.32 \mathrm{kPa}$ and for $\mathrm{C} \mathrm{Cdl}_{2}: \mathrm{Xe}: \mathrm{Ne}=22 \mathrm{~Pa}: 4 \mathrm{kPa}$ : $101.3 \mathrm{kPa}$ mixture at a total mixture pressure of $105.322 \mathrm{kPa}$ at which the maximum value was reached in the experiments (Table 1).

In the integral of collisions of electrons with atoms and molecules, the following processes are taken into account: elastic scattering, excitation of energy levels of the $\mathrm{Ne}$ atom with a threshold energy equal to $16.62 \mathrm{eV}, 16.67 \mathrm{eV}(1 \mathrm{~s} 4), 16.84 \mathrm{eV}$ (1s2), $18.72 \mathrm{eV}(2 \mathrm{p}), 20.0 \mathrm{eV}(2 \mathrm{~s}+3 \mathrm{~d}), 20.65 \mathrm{eV}(3 p)$ and ionization of the neon atom (threshold energy $21.56 \mathrm{eV}$ ); elastic scattering and excitation of electronic states of a xenon atom with threshold energies: $3.4 \mathrm{eV}, 8.31 \mathrm{eV}, 8.44 \mathrm{eV}, 9.69 \mathrm{eV}, 10.0 \mathrm{eV}$, $11.0 \mathrm{eV}, 11.7 \mathrm{eV}$, ionization of xenon atoms with a threshold energy of $12.12 \mathrm{eV}$, dissociative excitation: $\mathrm{B}^{2} \Sigma_{1 / 2^{-}}^{+}$states of cadmium monoiodide molecules (threshold energy $4.986 \mathrm{eV}$ ), cadmium atoms $\lambda=479.991 \mathrm{~nm}$ and $\lambda=508.582 \mathrm{~nm}$ (threshold energy $6.386 \mathrm{eV}$ ): ionization of cadmium diiodide, dissociative ionization with the formation of ions: cadmium diiodide, cadmium monoiodide, cadmium and iodine (threshold energies - $10 \mathrm{eV}, 11 \mathrm{eV}, 13 \mathrm{eV}, 14 \mathrm{eV}$, respectively). Data on the absolute values of the effective cross sections of these processes, as well as their dependences on the electron energy, were taken from the database [20] and works [13, 14, 15].

The electric field strength $(E)$ and the reduced electric field on the plasma (E/N) at which the maximum brightness of the emission in the spectral band $\left(\lambda_{\max }=650 \mathrm{~nm}\right)$ of the cadmium monoiodide molecule was observed in the experiment in a mixture of cadmium diiodide vapor and neon and a mixture of cadmium diiodide vapor, neon and a small addition of xenon were $1.8 \cdot 10^{6} \mathrm{~V} / \mathrm{m}, 148.9 \mathrm{Td}$ and $144.0 \mathrm{Td}$, respectively. They were determined by the method described by us in the article [21].

Figs. 6-7 show the dependences of the mean energy of electrons on the values of the parameter $\mathrm{E} / \mathrm{N}$ and the rate constants of 
dissociative excitation by electrons of the $\mathrm{B}^{2} \Sigma_{1 / 2}^{+}-$ state of cadmium monoiodide molecules. With an increase in the parameter $E / N$, the values of the mean electron energy and the rate constants of the excitation of molecules both for the binary mixture and for the ternary mixture increase. However, they are higher for a double mixture than for a triple mixture. For the values of the reduced electric field strength at which the experiment was carried out, they had values of $16.18 \mathrm{eV}$ and $13.05 \mathrm{eV}$ and $10.18 \cdot 10^{-15} \mathrm{~m}^{3} / \mathrm{s}$ and $8.921 \cdot 10^{-15} \mathrm{~m}^{3} / \mathrm{s}$, respectively.

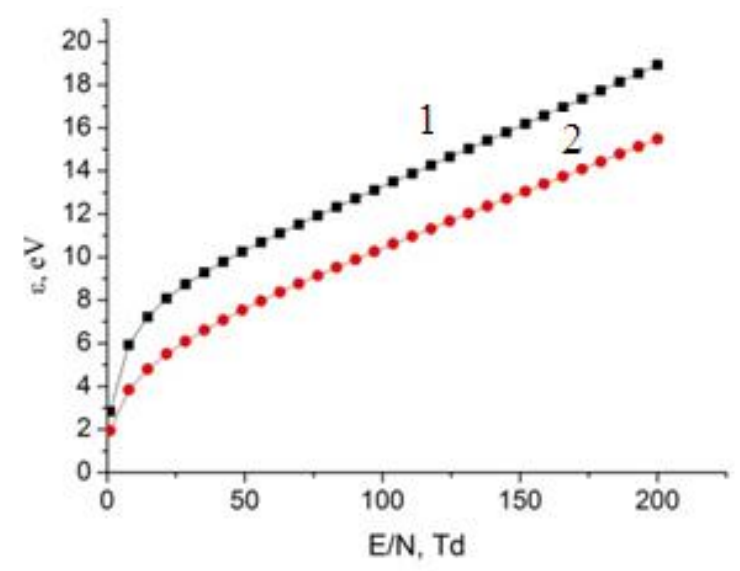

Figure 6: The dependence of the mean energy of electrons on the parameter $\mathrm{E} / \mathrm{N}$ in a plasma on a mixture: $1-\mathrm{Cdl}_{2}-\mathrm{Ne}=20 \mathrm{~Pa}: 101.3 \mathrm{kPa}$ at a total mixture pressure of $101.320 \mathrm{kPa}, 2-\mathrm{Cdl}_{2}: \mathrm{Xe}: \mathrm{Ne}=$ $22 \mathrm{~Pa}: 4 \mathrm{kPa}: 101,3 \mathrm{kPa}$ at a total mixture pressure of $105.322 \mathrm{kPa}$.

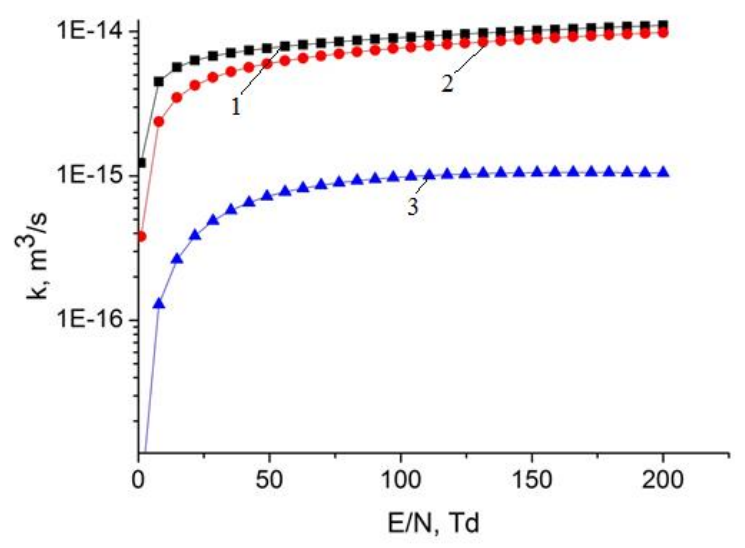

Figure 7: The dependence of the rate constant of dissociative excitation by electrons of the $\mathrm{B}^{2} \Sigma_{1 / 2}^{+}-$ state of cadmium monoiodide molecules on the parameter $\mathrm{E} / \mathrm{N}$ in plasma in a mixture: $1-\mathrm{Cdl}_{2}-\mathrm{Ne}$ $=20 \mathrm{~Pa}: 101.3 \mathrm{kPa}$ at a total mixture pressure of 101.320 kPa, 2- $\mathrm{Cdl}_{2}: \mathrm{Xe}: \mathrm{Ne}=22 \mathrm{~Pa}: 4 \mathrm{kPa}: 101.3$ $\mathrm{kPa}$ at a total mixture pressure of $105,322 \mathrm{kPa}, 3-$ dependence of the rate constant of excitation by electrons of the metastable state of xenon (threshold energy $8.31 \mathrm{eV}$ ) on the parameter $\mathrm{E} / \mathrm{N}$ in the plasma in a mixture - $\mathrm{CdI}_{2}: \mathrm{Xe}: \mathrm{Ne}=22 \mathrm{~Pa}: 4$ $\mathrm{kPa}: 101.3 \mathrm{kPa}$ at a total mixture pressure of $105.322 \mathrm{kPa}$.

The specific losses of the discharge power due to dissociative excitation by electrons of the $\mathrm{B}^{2} \Sigma_{1 / 2}^{+}-$ state of cadmium monoiodide molecules for a mixture of cadmium diiodide vapor with neon (Fig. 8) are higher than those for a mixture of cadmium diiodide vapor with neon and xenon (Fig. 9, curve 1). They reach maximum values of $14.78 \%$ and $4.44 \%$, respectively, for the reduced electric field $\mathrm{E} / \mathrm{N}=1 \mathrm{Td}$. At the same time, the specific losses of the discharge power for the excitation of the metastable state of xenon $\left(E_{\text {thr. }}=8.31 \mathrm{eV}\right.$ ) have higher values (Fig. 9, curve 2). For the reduced electric field $E / N=1 \mathrm{Td}$, they have a value of $20.45 \%$ (Fig. 9, curve 2). At the values of the reduced electric field 148.9 and $144.0 \mathrm{Td}$, at which the experimental studies were carried out and for which the brightness of the spectral emission band of $\mathrm{Cdl}(\mathrm{B} \rightarrow \mathrm{X})$ for a mixture of cadmium diiodide vapor with neon had a value in relative units of 0.8 . For a mixture of cadmium diiodide with neon and addition of xenon 1 (Table 1), the specific losses of the discharge power due to dissociative excitation by electrons of the $\mathrm{B}^{2} \Sigma_{1 / 2}^{+}-$ states of cadmium monoiodide molecules and the metastable state of xenon atoms $\left(E_{\mathrm{thr}}=8.31 \mathrm{eV}\right)$ were $0.02 \%$ and $0.73 \%$, respectively.

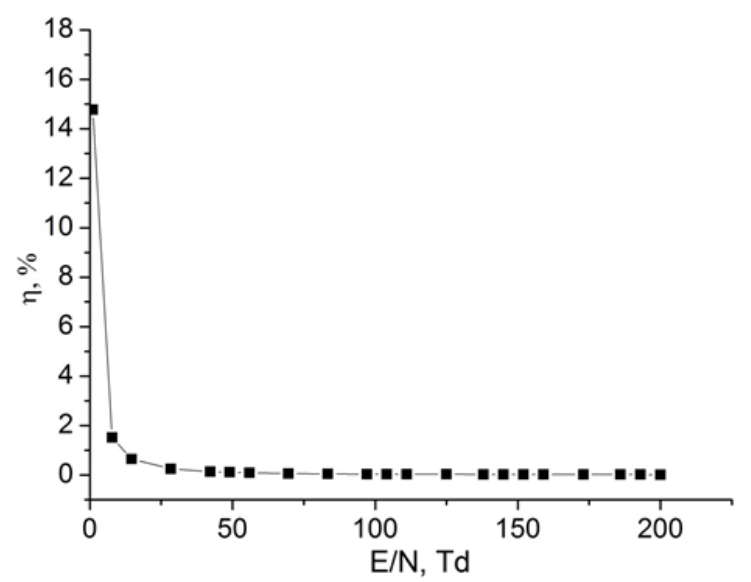

Figure 8: Specific losses of the discharge power due to dissociative excitation by electrons of the $\mathrm{B}^{2} \Sigma_{1 / 2}^{+}$- state of cadmium monoiodide molecules in plasma on a mixture $\mathrm{CdI}_{2}-\mathrm{Ne}=20 \mathrm{~Pa}$ : $101.3 \mathrm{kPa}$ at a total mixture pressure of $101,320 \mathrm{kPa}$.

Due to the fact that the specific power of discharge losses for the excitation of a metastable state of xenon is much higher (by 39 times) the specific power of the discharge losses for dissociative excitation by electrons of the $\mathrm{B}^{2} \Sigma_{1 / 2}^{+}-$ states of cadmium monoiodide molecules in a mixture with an additive xenon and the brightness 
of the emission of Cdl* molecules under experimental conditions are higher (Table 1), it can be assumed that the increased brightness of the emission in the mixture with the addition of xenon is associated with an additional process of population of the $\mathrm{B}^{2} \Sigma_{1 / 2}^{+}$- state of cadmium monoiodide molecules, and namely with the process of dissociative excitation of the $\mathrm{B}^{2} \Sigma_{1 / 2}^{+}-$ state of cadmium monoiodide molecules upon collision of xenon atoms in a metastable state with cadmium diiodide molecules (reaction 3).

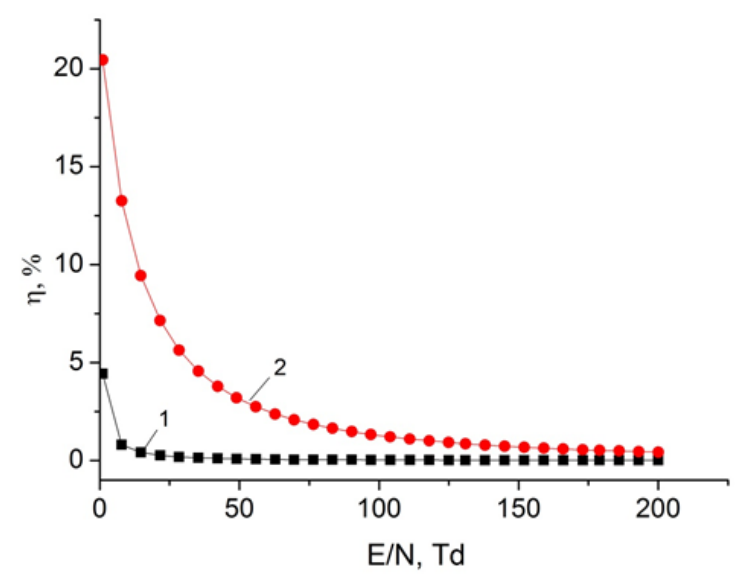

Figure 9: Specific losses of the discharge power in the plasma in a $\mathrm{Cdl}_{2}$ : $\mathrm{Xe}: \mathrm{Ne}=22 \mathrm{~Pa}: 4 \mathrm{kPa}: 101.3$ $\mathrm{kPa}$ mixture at a total mixture pressure of 105,322 $\mathrm{kPa}$ : 1- dissociative excitation by electrons of the $\mathrm{B}^{2} \Sigma_{1 / 2}^{+}$- states of cadmium monoiodide molecules, 2 - excitation of the metastable state of xenon $\left(E_{\text {thr. }}=8.31 \mathrm{eV}\right)$.

\section{Conclusions}

Spectroscopic diagnostics of a gas-discharge plasma of a dielectric barrier discharge of atmospheric pressure on mixtures of cadmium diiodide vapor with neon and xenon revealed intense quasi-continuous radiation with a maximum at $\lambda=655 \mathrm{~nm}$ of cadmium monoiodide molecules, the main part of which is concentrated in the 635-660 $\mathrm{nm}$ region. In addition, the spectra of the mixtures contain intense radiation in the ultraviolet region - the spectral band of the Xel $(B \rightarrow X)$ molecule $(\lambda=253 \mathrm{~nm})$, the lines of cadmium and iodine atoms at $\lambda=228.8$ and $206.2 \mathrm{~nm}$, respectively. Optimal for obtaining maximum brightness in the spectral band at $\lambda=655 \mathrm{~nm}$ of cadmium monoiodide molecules is the $\mathrm{Cdl}_{2} / \mathrm{Xe} /$ $\mathrm{Ne}$ mixture for which the ratio of the partial pressures of its components corresponds to: 22 $\mathrm{Pa} / 4 \mathrm{kPa} / 101.3 \mathrm{kPa}$. It was found that the reason for the increase in the brightness of the emission of exciplex cadmium monoiodide molecules in this mixture is the transfer of energy from xenon atoms in a metastable state to cadmium diiodide molecules with the formation of exciplex cadmium monoiodide molecules.

Gas-discharge plasma of a high-frequency dielectric barrier discharge of atmospheric pressure in mixtures of cadmium diiodide vapor with neon and xenon can be used to create a multi-wave excilamp emitting spectral bands and lines in the ultraviolet and visible spectral ranges, which, in turn, can be used to stimulate the photosynthesis process in plants as well as to inactivate viruses and cells that negatively affect their growth.

\section{References}

[1] E. W. McDaniel and W. L. Nighan, "Gas Lasers" (New York: Academic Press), 1982.

[2] V.S. Shevera, A.N. Malinin, A.K. Shuaibov, "Investigation of the excitation and quenching state of $\mathrm{Cdl}^{*}$ in a pulsed discharge through a dielectric", J. Appl. Spec., vol. 39, no. 3, 1983.

[3] A.N. Konoplev, V.A. Kelman, V.S. Shevera, "Investigation of radiation from a pulsed discharge in mixtures of $\mathrm{ZnI}_{2}, \mathrm{Cdl}_{2}$, and $\mathrm{Hgl}_{2}$ with helium and neon", J. Appl. Spec., vol. 39, no. 2, 1983.

[4] A.N. Malinin, A.V. Polyak, “Optical characteristics of a barrier discharge plasma on mixtures of cadmium diiodide vapors with gases", Opt. Spectrosc., vol. 99, no. 6, 2005.

[5] N.N. Guivan, A.N. Malinin, "Spectroscopic diagnostics of the plasma of a barrier discharge on mixtures of zinc diiodide vapor with inert gases", Opt. Spectrosc., vol. 99, no. 5,2005.

[6] I.K. Kikoin, "Tables of physical quantities. Directory" (M.: Atomizdat), 1976.

[7] A.A. Malinina, A.N. Malinin, A.K. Shuaibov, "Emision characteristics of gas -discharge plasma of atmospheric pressure dielectric barrier discharge of zinc diodide vapor with neon and xenon mixture", $22^{\text {nd }}$ Symposium on Application of Plasma Processes and $11^{\text {th }}$ EU-Japan Joint Symposium on Plasma Processing, Book of Contributed Papers Strbske Pleso, Slovakia 18-24 January, 2019.

[8] Y.S. Akishev, A.V. Demyanov, V.B. Karalnik, M.V. Pankin, N.l. Trushkin, "Pulsed Regime of the Diffusive Mode of a Barrier Discharge in Helium", Plas. Phys. Rep. vol.27, 20011648171, 2001. 
[9] R.W. Pearse, A.G. Gaydon, "The identification of molecular spectra”, (L.: Chopman Holl LTD), 1963.

[10] A. A. Malinina, A.N. Malinin, "Experimental and theoretical characterization of dielectric barrier discharge in diode mercury, xenon and helium gaseous mixture" American J. Optics and Photonics, vol. 4, 2016.

[11] A.N. Zaydel, V.K.Prokofiev, S.M. Raisky, V.A. Glorious, E.Ya. Shreider, "Spectral line tables", (Moscow: Nauka), 1977.

[12] Ch.M. Rhodes, “Excimer lasers”, (M: Mir), 1981.

[13] A.N. Konoplev, N.N. Chavarga, V.N. Slavik, V.S. Shevera, "Dissociative excitation of CdJ2 by electron impact", Tech. Phys. Lett., vol. 15, no. 22, 1989.

[14] Yu.M. Smirnov, "Inelastic collisions of slow electrons with cadmium (II) iodide molecules", High Energy Chem., v. 34, no. 6, 2000.

[15] A.N. Konoplev, V.N.Slavik, V.S. Shevera, "Dissiative ionization of CdJ2 molecules by electron impact", Tech. Phys. Lett., v. 16, no. 19, 1990.

[16] G.A.Volkova, G.N. Zvereva, "Investigation of the parameters of the barrier discharge in the mixtures $\mathrm{Kr}-\mathrm{I}_{2}, \mathrm{Xe}-\mathrm{I}_{2}$ ", Opt. Spectrosc., vol. 96, no. 3, 2004.

[17] C. Jianwen, F. Shufen, L. Miaohong, “Efficient operation of Blumlein-discharge-excited $\mathrm{XeCl}$ laser", Appl. Phys. Lett., vol. 37, 1980.

[18] Yu.P. Raizer, "Gas Discharge Physics" (Moscow: Nauka) 1987.

[19] G. J. M. Hagelaar and L. C. Pitchford, "Solving the Boltzmann equation to obtain electron transport coefficients and rate coefficients for fluid models", Plasma Sources Sci Technol., vol. 14, 2005.

[20] https://www.bolsig.laplace.univ-tlse.fr, Version of Sep. 2020

[21] A.O. Malinina, O.K. Shuaibov, O.M. Malinin, "The mechanism of increasing the radiation power of a gas discharge lamp on mixtures of mercury dichloride, neon and nitrogen vapors in the bluegreen spectral range", Ukr. J. Phys., vol.64, no.9, 2019. (a) (1)

Open Access. This article is licensed under a Creative Commons Attribution 4.0 International License, which permits use, sharing, adaptation, distribution and reproduction in any medium or format, as long as you give appropriate credit to the original author(s) and the source, provide a link to the Creative Commons license, and indicate if changes were made. The images or other third party material in this article are included in the article $s$ Creative Commons license, unless indicated otherwise in a credit line to the material. If material is not included in the article's Creative Commons license and your intended use is not permitted by statutory regulation or exceeds the permitted use, you will need to obtain permission directly from the copyright holder. To view a copy of this license, visit: http://creativecommons.org/licenses/by/4.0/. 